Conference Paper

\title{
Study the Effect of Smoking on the Potential of Human Resources
}

\author{
Sunardi*, Muhammad Rezki Agus Kurniawan , MT Safirin \\ Industrial Engineering Department, Faculty of Engineering, Universitas Pembangunan Nasional "Veteran" \\ Surabaya, East Java, Indonesia
}

${ }^{*}$ Corresponding author:

E-mail: sunardi.ti@upnjatim.ac.id

\begin{abstract}
Human resources have an important role in development so that the potential need to be developed. Fatigue is a normal condition in everyday life. In general, fatigue can be divided into two namely, physical fatigue (physical fatigue) and mental fatigue (mental fatigue). Many factors can cause fatigue in humans, one of which is smoking behavior. Smoking in adolescence, especially working age will disrupt fitness, especially cardiorespiratory endurance. One method that can support this research is the Response Surface Methodology method. The results showed that smoking for nine years with moderate consumption of cigarettes at the age of work did not affect physical or mental fatigue, but there was a tendency to increase a little mental and physical fatigue. Improved predictability can significantly reduce physical endurance.
\end{abstract}

Keywords: Smoking, mental health, physical fatigue

\section{Introduction}

Human resources are the most valuable organizational assets so they need to be prepared since learning. Therefore the potential must be maintained and increased. The potential of human resources can be seen based on indicators of physical endurance and mental health. Physical endurance is measured by the speed of the heart rate, and mental health is measured by accuracy and speed of working. Human resources are very important in developing industrial resources.

Fatigue is a normal and natural condition in daily life that is usually characterized by an increasingly rapid heartbeat (Nelesen et al., 2008). Many factors can affect cardiorespiratory endurance at work age, one of which is smoking behavior (de Borba et al., 2014). Smoking in adolescence, especially working age will interfere with fitness, especially cardiorespiratory endurance because of the effects of substances contained therein. Most Indonesians, both teenagers, and adults think that there is no effect of smoking on their bodies until they reach middle age. Though the long-term effects of smoking are very dangerous for humans, one of the cardiovascular disorders (Papathanasiou et al., 2014). From the background can be arranged issues raised in this study, namely how the influence of the duration of smoking on the level of physical and mental fatigue in active smokers at work age. Szatkowski \& McNeill (2015), that find more than doubled smoking rates among the English population with mental health disorders compared to the English population without mental health disorders. This is based on the background that the younger generation at the age of fewer than 25 years is the future of the nation and state. As said by Mansikkamaki, et al (2015), that change is mental and physical health due to changes in health investments take time to materialize. Furthermore Taylor, et al (2014) that finds general evidence for reduced depression, anxiety, and stress after smoking cessation interventions. Some research shows that age affects the strength of back muscles in adults aged 40 to 60 years, meaning that before the age of 40 years has not affected. But of course, the decline is with a different rhythm depending on factors environmental conditions. 
The material of cigarette is tobacco, and according to WHO (2009), tobacco use explains $17.9 \%$ of all deaths and physical inactivity explains $7.7 \%$ of all deaths. As a raw material cigarette, tobacco is responsible for so many deaths compared to other herbal plants. The nikine content of the plant's nicotine content is left $64 \%$, stem $18 \%$, root $13 \%$, and flower $5 \%$.

Pulat (1992), the overstressed muscle will develop a painful phenomenon called the muscular fatique, and this condition is acute and localized. On the other hand, overburdened cognitive functions, human beings develop mental fatique, accompanied by a general sensation of weariness. It is heavy and overworked. Both monotony and excessive use of mental function may cause these symptoms.

Daily smoking was more often associated with individual spot either demanding less endurance, associated with less frequent participation in the competition. It is not clear whether these differences by type of sport are because smoking is perceived as less likely to impair performance or reflects peer influence, with plays an important part in adolescent smoking (Jackson, 1997).

The purpose of this study was to determine whether there is an influence on the duration of smoking on physical fatigue and mental health when doing activities.

The hypothesis of the research are:

1. There is a significant influence of smoking duration on physical fatigue at work age

2. There is a significant influence of smoking duration on mental health when working at work age

3. The longer a person smokes the faster he will experience a rapid decrease in physical and mental health.

\section{Research Method}

This research was conducted on a population of young people aged between 19 to 23 years with a duration of smoking 1 to 9 years. Samples were taken of 30 subjects each. The subjects consisted of students, factory workers in Kutorejo District, Mojokerto Regency. The sampling technique was purposive sampling. The study design uses a single factor with four levels as independent variables, namely:

Level 1: No smoking

Level 2: Smoking 1-3 years

Level 3: Smoking $>3-6$ years

Level 4: Smoking> 6 - 9 years

And as dependent variables, namely 1 \} physical endurance, is measured by the speed of the heart rate, 2) mental health is measured by accuracy and speed of work.

Analysis of data use response surface methodology (RSM) according to Joshi et al (1988), RSM is a method to optimize complex systems where at best one can be only evaluated the function being, often via a simulation experimental process.

\section{Results and Discussion}

\section{The result of research}

Data on Heart Rate and Mental Test Results are shown in table 1 and table 2.

Table 1. Heart Rate test results

\begin{tabular}{ccccccccc}
\hline No & \multicolumn{3}{c}{ Physical test (heart rate) } & \multicolumn{4}{c}{ Mental test } \\
& Level 1 & Level 2 & Level 3 & Level 4 & Level 1 & Level 2 & Level 3 & Level 4 \\
\hline 1 & 133 & 129 & 149 & 153 & 53 & 64 & 60 & 58 \\
2 & 112 & 145 & 139 & 169 & 56 & 65 & 56 & 60 \\
3 & 105 & 139 & 143 & 158 & 49 & 63 & 57 & 49 \\
4 & 128 & 142 & 141 & 170 & 54 & 59 & 58 & 65 \\
5 & 123 & 146 & 140 & 168 & 58 & 54 & 59 & 68 \\
To be continued & & & & & & & \\
\hline
\end{tabular}


1stICESET 2020

\begin{tabular}{ccccccccc}
\hline 6 & 111 & 131 & 130 & 167 & 59 & 53 & 60 & 66 \\
7 & 102 & 136 & 135 & 144 & 52 & 54 & 58 & 57 \\
8 & 135 & 141 & 130 & 172 & 50 & 53 & 50 & 70 \\
9 & 125 & 138 & 142 & 162 & 48 & 49 & 55 & 69 \\
10 & 137 & 142 & 147 & 156 & 52 & 62 & 62 & 48 \\
11 & 135 & 137 & 146 & 144 & 65 & 57 & 57 & 66 \\
12 & 139 & 139 & 146 & 155 & 56 & 62 & 60 & 65 \\
13 & 131 & 142 & 145 & 163 & 60 & 57 & 51 & 62 \\
14 & 138 & 140 & 141 & 143 & 56 & 60 & 51 & 60 \\
15 & 115 & 135 & 136 & 145 & 60 & 68 & 48 & 57 \\
16 & 120 & 137 & 149 & 153 & 58 & 60 & 65 & 70 \\
17 & 136 & 141 & 137 & 158 & 51 & 59 & 56 & 65 \\
18 & 101 & 147 & 141 & 157 & 50 & 48 & 57 & 64 \\
19 & 115 & 139 & 143 & 148 & 52 & 59 & 60 & 69 \\
20 & 125 & 140 & 148 & 152 & 54 & 57 & 62 & 63 \\
21 & 132 & 137 & 142 & 162 & 56 & 65 & 58 & 62 \\
22 & 138 & 138 & 139 & 155 & 52 & 62 & 58 & 67 \\
23 & 123 & 140 & 147 & 149 & 56 & 60 & 67 & 68 \\
24 & 113 & 133 & 140 & 162 & 66 & 65 & 65 & 62 \\
25 & 120 & 132 & 143 & 151 & 62 & 68 & 60 & 57 \\
26 & 107 & 146 & 131 & 150 & 71 & 56 & 49 & 58 \\
27 & 120 & 141 & 138 & 154 & 56 & 70 & 70 & 65 \\
28 & 99 & 130 & 140 & 160 & 48 & 68 & 58 & 52 \\
29 & 148 & 147 & 146 & 149 & 70 & 62 & 66 & 62 \\
30 & 93 & 128 & 149 & 152 & 56 & 60 & 57 & 56 \\
$M e a n$ & 122 & 138.6 & 1441.4 & 156 & 55.6 & 58.3 & 60 & 62 \\
\hline
\end{tabular}

\section{Descriptive Analysis}

Descriptive analysis is carried out based on the mean and standard deviation for each level as in table 2 and table 3 this below:

Table 2. Categories of physical fatigue at various levels

\begin{tabular}{lcccc}
\hline Categories & \multicolumn{4}{c}{ \% Sum of Subject } \\
& Level 1 & Physical Fatigue (heart rate) & \\
& Level 2 & Level 3 & Level 4 \\
\hline High & 13 & 16 & 30 & 33 \\
Middle & 70 & 70 & 56 & 67 \\
Low & 17 & 14 & 14 & 0 \\
Mean & 122 & 138.6 & 141.4 & 156 \\
\hline
\end{tabular}

Table 3. Categories of mental fatigue at various levels

\begin{tabular}{|c|c|c|c|c|}
\hline \multirow[t]{2}{*}{ Categories } & \multicolumn{4}{|c|}{$\begin{array}{l}\text { \% Sum of Subject } \\
\text { Mental Fatigue }\end{array}$} \\
\hline & Level 1 & Level 2 & Level 3 & Level 4 \\
\hline High & 17 & 23 & 17 & 40 \\
\hline Middle & 73 & 7 & 66 & 50 \\
\hline Low & 10 & 70 & 17 & 10 \\
\hline Mean & 56.2 & 58.3 & 60 & 62 \\
\hline
\end{tabular}


Table 4. Optimum heart rate and mental test result

\begin{tabular}{ccc}
\hline Tipe Responden & Sum of heart rate (minute) & MentalTest Value \\
\hline Level 1 (No Smoking) & 121 & 55.999 \\
Level 2 (Smoking > 1-3 years) & 126 & 55.998 \\
Level 3 (Smoking > 3-6 years & 140 & 56.0 \\
Level 4 (Smoking 6-9 years & 1561140 & 56.0 \\
\hline \hline
\end{tabular}

\section{Inferential Analysis}

Inferential analysis was performed using the response surface regression method with the help of Minitab 17 software as follows:

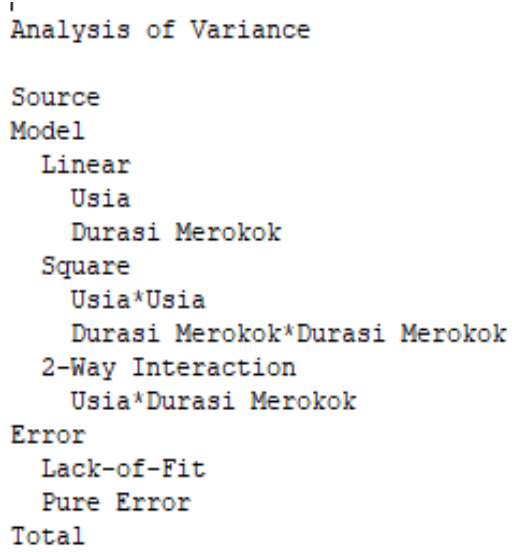

Model Summary

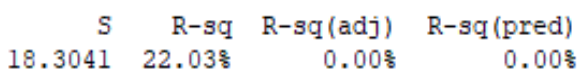

$\begin{array}{lrrrrrr}\text { Term } & \text { Effect } & \text { Coef } & \text { SE Coef } & \text { T-Value } & \text { P-Value } & \text { VIF } \\ \text { Constant } & & 113.00 & 8.19 & 13.80 & 0.000 & \\ \text { Usia } & -6.57 & -3.29 & 6.47 & -0.51 & 0.627 & 1.00 \\ \text { Durasi Merokok } & 3.16 & 1.58 & 6.47 & 0.24 & 0.814 & 1.00 \\ \text { Usia*Usia } & -0.13 & -0.06 & 6.94 & -0.01 & 0.993 & 1.02 \\ \text { Durasi Merokok*Durasi Merokok } & 16.38 & 8.19 & 6.94 & 1.18 & 0.277 & 1.02 \\ \text { Usia*Durasi Merokok } & 9.00 & 4.50 & 9.15 & 0.49 & 0.638 & 1.00\end{array}$

Figure 1. Analysis of variance heart rate 


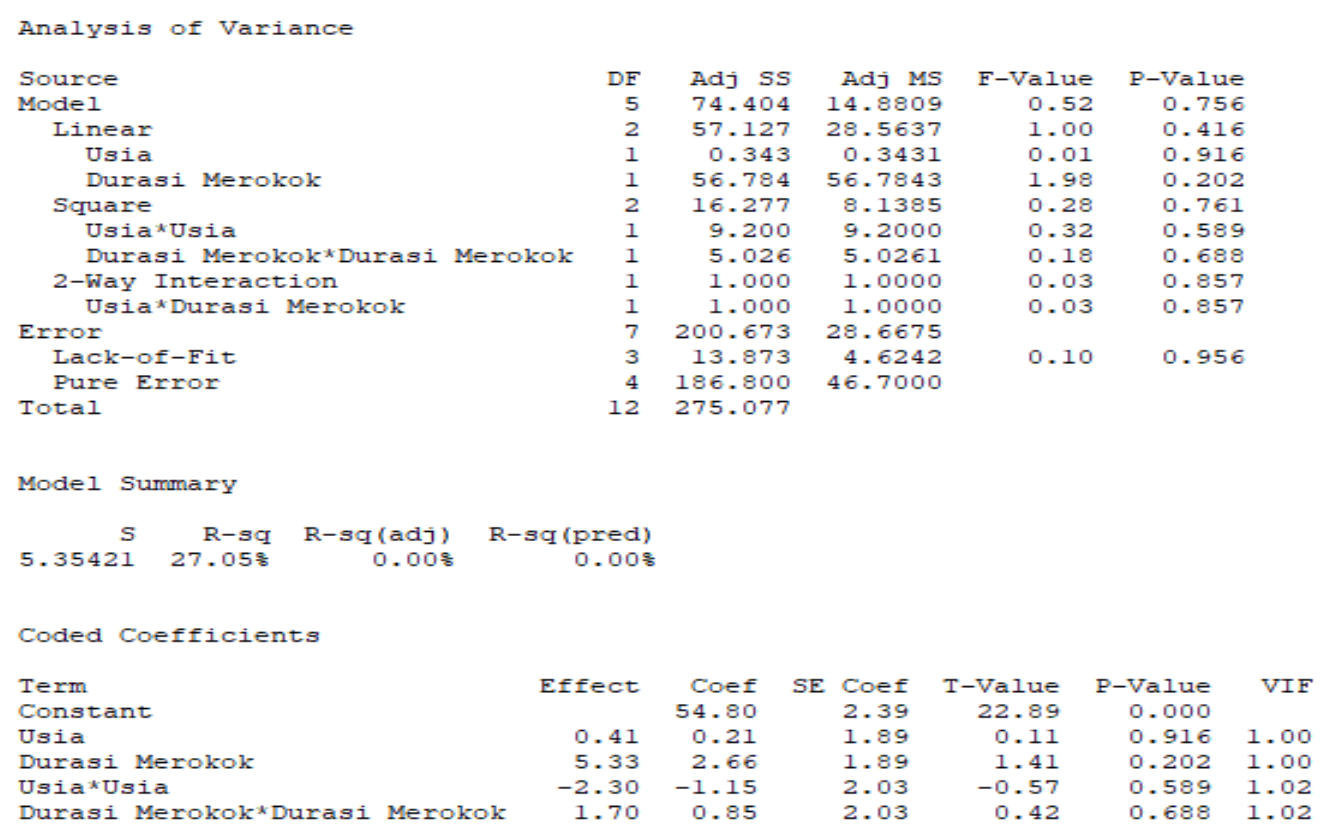

Figure 2. Analysis of variance mental fatigue

\section{Result and Discussion}

Descriptive analysis as in Table 3 illustrates that nonsmokers (level 1) have the lowest means in physical endurance (heart rate) and subsequently increase, and this is in line with inferential analysis using the response surface regression method that the duration of smoking does not affect by mental fatigue and physical fatigue (figure 2). This is contrary to Mansikkamaki, et al (2015) and Kim, et al (2012), that changes in health investments take time to materialize for cigarette consumption, for physical activity. This is likely due to the time required for smoking to be inadequate and the relatively small consumption of cigarettes so that further studies are needed in the future for further research. Likewise for table 4 regarding the means of mental fatigue to increase even though it is not as significant as inferential analysis using the response surface regression method (figure 2).

In line with Taylor, et al (2014), it finds genital evidence for reduced depression, anxiety, and stress after smoking cessation interventions. Reverse-causality is likely to occur as smoking rates are twice as high among adults with depression or anxiety disorders. According to Durakovic, et al (2012) although differences in smoking history and duration of smoking as evidence early and persist as a steady detrimental effect of the chronic smoking habit.

From the overall analysis of this study, it was found that the most optimal proportion of conditions for heart rate while performing workloads is not smoking because there is a tendency for people who smoke to increase the increase in heart rate which can produce 121 heartbeats/minute. This condition indicates that the heart is not working too hard to pump blood needs throughout the body due to the condition of the heart and lungs that still have a normal working capacity.

This study obtained the most optimal proportion of mental conditions when performing clerical speed and accuracy tests are people who have smoked 3-9 years by producing an optimum number of 56.0. Although the difference in numbers is less than 0.1 compared to people who don't smoke longer or people who don't smoke. But these figures should be calculated accordingly. These results also concluded that there was no significant effect of the duration of smoking on mental fatigue at work age, especially at the age of 19-23 years. 


\section{Conclusion}

Smoking for nine years with moderate cigarette consumption does not affect physical fatigue or mental endurance, but there is a tendency to increase a little mental and physical endurance. However, it is still recommended to avoid smoking because there is a tendency to decrease physical endurance, so if cigarette consumption is increased it can be predicted to reduce endurance significantly physical.

\section{Acknowledgment}

This work was financially supported by Industrial Engineering Department, Faculty of Engineering, UPN “Veteran" East Java Surabaya, Indonesia. Therefore, we are grateful for this funding and support of this research.

\section{References}

de Borba, A. T., Jost, R. T., Gass, R., Nedel, F. B., Cardoso, D. M., Pohl, H. H., Reckziegel, M. B., Corbellini, V. A., \& Paiva, D. N. (2014). The influence of active and passive smoking on the cardiorespiratory fitness of adults. Multidisciplinary respiratory medicine, $9(1)$, 34. doi.org/10.1186/2049-6958-9-34

Durakovic, M. M. et al. (2012). The effect of cigarette smoking history on muscular and cardiorespiratory endurance. Journal of Additive Deseases, 31(4), 389-396. doi.org/10.1080/10550887.2012.735567

Jackson, C. (1997). Initial and experimental stages of tobacco and alcohol use during late childhood: relation to peer, parent, and personal risk factors. Addictive Behaviors, 22(5), 685-698. doi.org/10.1016/S0306-4603(97)00005-1

Joshi, S., Sherali, H. D., \& Tew, J, D. (1998). An enhanced response surface methodology (rsm) algorithm using gradient deflection and second-order search strategies. Computers and Operations Research, 25(7-8), 531-541. doi.org/10.1016/S03050548(98)00014-8

Mansikkamaki, K., et al. (2015). Long-term effect of physical activity on health-related quality of life among menopausal women: a 4year follow-up study to randomized controlled trial. BMJ Open, 5(9). DOI: 10.1136/bmjopen-2015-008232

Nelesen, R., Dar, Y., Thomas, K., \& Dimsdale, J. E. (2008). The relationship between fatigue and cardiac functioning. Archives of internal medicine, 168(9), 943-949. doi.org/10.1001/archinte.168.9.943

Papathanasiou, G., Mamali, A., Papafloratos, S., \& Zerva, E. (2014). Effect of smoking on cardiovascular function and carbon monoxide. Health Science Journal, 8(2), 274

Pulat, B. M. (1997). Fundamentals of industrial ergonomics: prentice-hall international series in industrial and systems engineering. Englewood Cliffs, N. J.: Prentice Hall

Szatkowski, L. \& McNeill, A. (2015). Diverging trends in smoking behaviours according to mental healt status. Nicotine Tob Res, 17(3), 356-360. doi: 10.1093/ntr/ntu173

Taylor, G., et al. (2014). Change in mental health after smoking cessation: systematic review and meta-analysis. BMJ (Clinical research ed.), 348, g1151. https://doi.org/10.1136/bmj.g1151 